\title{
EFFECT OF ELECTROCONVULSIVE THERAPY ON SERUM SEROTONIN LEVEL IN PATIENTS WITH TREATMENT- RESISTANT MAJOR DEPRESSIVE DISORDER
}

\author{
Parvin Agha Mohammad Hasani1, Fatemeh Mohseni Moghadam², Mohammadreza Mokhtaree ${ }^{3}$, Mohammad Nazer 4 \\ 1 Department of Psychiatry, Rafsanjan University of Medical Sciences, Rafsanjan, Iran. \\ ${ }^{2}$ Faculty of Paramedicine, Department of Basic Sciences, Rafsanjan University of Medical Sciences, Rafsanjan, Iran. \\ ${ }_{3}^{3}$ MSc of Educational Psychology, Social Determinants of Health Research Center, Rafsanjan University of Medical Sciences, Rafsanjan, \\ Iran. \\ ${ }^{4}$ Department of Psychiatry, Rafsanjan University of Medical Sciences, Rafsanjan, Iran.
}

\section{BACKGROUND}

ABSTRACT

Previous studies have reported contrasting results about the effects of ECT on serotonin levels. We wanted to investigate the therapeutic effects of ECT on plasma serotonin levels in patients with major depressive disorder.

\section{METHODS}

In this cohort study, 36 patients with MDD were allocated to ECT group ( $\mathrm{n}=21)$ and Non-ECT group ( $\mathrm{n}=15)$. Plasma serotonin levels of the ECT group were measured before ECT, 15 minutes and 2-, 6-, and 24-hours, 16- and 30-days after treatment. In the Non-ECT group, measurement of serotonin was performed before drug therapy, 16 days and 30 days after drug therapy. Data was analysed with SPSS-16 using independent t-test, and repeated with ANOVA at a significance level of $\mathrm{p} \leq 0.050$.

\section{RESULTS}

The mean $( \pm \mathrm{SD})$ age was $34.42 \pm 13.77$. In ECT group, the mean plasma serotonin levels before ECT, 15 minutes and 2-, 6-, and 24hours, 16- and 30-days after treatment were $197.66 \pm 81.24,211.86 \pm 79.30,204.86 \pm 62.14,246.14 \pm 98.60,234.76 \pm 101.42$, $263.71 \pm 100.14$ and $263.81 \pm 101.63 \mathrm{ng} / \mathrm{ml}$ respectively $(\mathrm{p}<0.007)$. In the non- ECT group, the mean serotonin levels before drug therapy, 16 days and 30 days after drug therapy were $198.93 \pm 84.38,198.40 \pm 84.98$ and $195.93 \pm 81.59 \mathrm{ng} / \mathrm{ml} \mathrm{respectively}(\mathrm{p}=$ 0.739). Mean plasma serotonin level 30 days after treatment in ECT group was higher than non-ECT group significantly ( $p=0.040$ ).

\section{CONCLUSIONS}

The results showed that plasma serotonin levels significantly increase following ECT in MDD patients. Perhaps, the faster effect of ECT than drug therapy is due to this issue. However, the rate of recovery in this study was not investigated.

HOW TO CITE THIS ARTICLE: Hasani PAM, Moghadam FM, Mokhtaree M, et al. Effect of electroconvulsive therapy on serum serotonin level in patients with treatment- resistant major depressive disorder. J. Evolution Med. Dent. Sci. 2019;8(16):1283-1286, DOI: $10.14260 /$ jemds/2019/286

\section{BACKGROUND}

Psychiatric disorders are currently the most common health issues in human societies.(1) Depression is the most prevalent psychiatric disorder affecting about $26 \%$ of the U.S. adult population. $(2,3)$ While this disorder can have genetic aetiology, it may also be caused by a variety of factors including nervous system problems, medications, environmental factors, certain diseases, stressors, social dissatisfactions, pessimism, low self-esteem, dependent personality disorder, failure in life, and anxiety.(4) Patients with depression are known to have low levels of serotonin metabolites in their cerebrospinal fluid (CSF) and brain tissue.(5) Since research on the aetiology of depression has introduced deficit in some monoamine neurotransmitters, e.g. norepinephrine, dopamine, serotonin, and histamine, to be responsible for the disorder, researchers of this field have started to focus on neurobehavioral systems, neural circuits, and neural regulation. Favourable effects of selective serotonin reuptake inhibitors (SSRIs), such as fluoxetine, and other serotonergic anti-depressants on the treatment of

'Financial or Other Competing Interest': None.

Submission 21-01-2019, Peer Review 17-03-2019,

Acceptance 22-03-2019, Published 22-04-2019.

Corresponding Author:

Mohammad Nazer,

Department of Psychiatry,

Rafsanjan University of Medical Sciences, Rafsanjan, Iran.

E-mail:nazerm47@gmail.com

DOI: $10.14260 /$ jemds $/ 2019 / 286$ depression have been well documented. Moreover, previous studies have suggested the involvement of serotonin, otherwise known as 5-hydroxytryptamine (5HT), in pathophysiology of depression.(6). Neurons of the central nervous system (CNS) are also capable of producing serotonin, which is later used to regulate appetite, sleep, temperature, mood, muscle contractions, and behaviours, enhance memory and learning, and control cardiovascular and endocrine system functioning. Identification of several serotonin receptor subtypes has encouraged the research community to find more specific treatments for depression. Serotonin receptors, ligand-gated ion channels present on cell membranes of neurons and other cells in animals, mediate the effects of serotonin and a variety of drugs. The serotonergic action ends with synaptic reuptake of serotonin which is in turn mediated through a specific serotonin monoamine transmitter released by pre-synaptic neurons. The use of various drugs (Including ecstasy, amphetamines, and cocaine), dextromethorphan, tricyclic anti-depressants, and SSRIs can prevent serotonin reuptake. Tryptophan and 5hydroxy tryptophan metabolite, which synthesize serotonin, can cross the blood-brain barrier. A number of medicines such as antidepressants, antipsychotics, anxiolytics, and antinausea and anti-migraine medications, and those used in delusional and cognitive disorders target serotonin. Electroconvulsive therapy (ECT) is considered an effective treatment for psychiatric disorders, especially endogenous (major) depressive, bipolar disorders and schizophrenia. Anti-depressant effects of ECT are associated with the 
generalized seizure, for a minimum of 15 seconds, that it induces.(7) Although the exact mechanism of action of ECT is not clear, it is believed to exert therapeutic effects through biological and physiological changes in the CNS and brain metabolism. (8,9) ECT has also been shown to have different effects on various chemical transmitters. However, such effects have not been fully understood yet.(10) While brain serotonin receptors used to be considered the focus for effectiveness of ECT, pre-clinical studies have revealed the method to elevate the regulatory levels of serotonin receptors. Antidepressants, on the other hand, reduce the mentioned levels. According to positron emission tomography scans of patients with depression, antidepressants decrease the amount of serotonin receptors in the brain. Meanwhile, the effects of ECT effect on these receptors are still unknown.(11) Since previous studies have reported contrasting results about the effects of ECT on serotonin levels, the present research aimed to investigate the therapeutic effects of ECT on plasma serotonin levels in patients with major depressive disorder.

\section{METHODS}

\section{Study}

This is a cohort study that done in psychiatry department of Moradi hospital (Rafsanjan, Iran, 2016-2017).

\section{Subjects}

The sample size was calculated 36 MDD patients based on formula that entered to study by convenience method. Patients were of both sexes and at the age of 23-55 years. Electroconvulsive therapy prescribed for 21 patients (ECT group). ECT did not prescribe for 15 patients due to neurological diseases, history of eye surgery in last 6 months or disagree to ECT (Non-ECT group). The diagnosis of MDD was confirmed based on the Diagnostic and Statistical Manual of Mental Disorders, Fifth Edition (DSM-5). Patients had a history of hospitalization, but had never received ECT. At the beginning of the study, informed consent was obtained from all patients. None of the participants had an experience of alcohol or substance abuse during the six months prior to the study. In order to eliminate the confounding effects of food items on serotonin levels, all subjects were asked to use similar diets. Hospitalized patients were briefed about serotonin-rich foods and were requested to avoid these food items along with foods promoting serotonin production, e.g., tomatoes, bananas, chocolate, cocoa, and walnuts. There was no any change in the treatment plan of the patients in two groups throughout the study.

\section{Procedure}

By the Synopsis of psychiatry Protocol,(6) patients received 68 sessions of ECT. The procedure was performed in Psychiatry Ward at 8 0'clock in the morning on even days. After ensuring the nil per os (NPO) status of the patients, they received muscle relaxants and anaesthetics (Sodium thiopental $3 \mathrm{mg} / \mathrm{kg} \mathrm{IV}$, succinylcholine chloride $0.4 \mathrm{mg} / \mathrm{kg} \mathrm{IV}$, and atropine $0.5 \mathrm{mg}$ IV) under the supervision of an anaesthesiologist. Bi-frontotemporal electrode placement was used. The ECT instrument (ARA121, made by Farsun-Ara
Company, Iran) uses a bipolar brief pulse square wave, Frequency: $70 \mathrm{~Hz}$ at 55 100\% energy, Pulse width: $1 \mathrm{msec}$, Duration: 0.5 to $3 \mathrm{sec}$, energy 30 to $50 \mathrm{j}$, current: 0.9 amps constant. The ECT process was done by ECT team (Consist of psychiatrist, anaesthesiologist, a technician of anaesthesiology, nurses). The ECT team was constant throughout the study.

\section{Measuring}

In ECT group, for measuring plasma serotonin level, $5 \mathrm{ml}$ blood sample were taken immediately before ECT, 15 minutes, 2, 6, and 24 hours, 16 and 30 days after the first ECT.

In Non-ECT group, $5 \mathrm{ml}$ blood sample were taken before drug therapy, 16 days and 30 days after beginning drug therapy. Blood samples were immediately sent to the laboratory and centrifuged at 3000 rounds per minute for 510 minutes. The blood plasma were poured into microtubes and maintained at $-20^{\circ} \mathrm{C}$ until analysis. Plasma serotonin levels were determined using a commercial kit (DLD Diagnostika, Hamburg, Germany) and based on the standard diagnostic and laboratory protocols.(12)

\section{Statistical Methods}

The data were presented in two sections: descriptive (Mean \pm SD) and inferential statistics. The skewness and kurtosis values were between $+2 /-2$ we can accept normal distribution. In addition, the p-value of Kolmogorov-Smirnov of data was> 0.05 except before treatment. So we used repeated measure test and T-test at a significant level of $p$ $\leq 0.05$. All of analyses were done by SPSS- 16 .

\section{RESULTS}

The mean $( \pm \mathrm{SD})$ age of the ECT and Non-ECT groups was $35.24 \pm 14.17$ and $33.26 \pm 13.59$ years, respectively. Independent t-test showed that there was no significant difference between two groups in terms of age $(p=0.678)$. According to Independent t-test, there was no significant difference between the two groups in terms of plasma serotonin before treatment $(\mathrm{p}=0.924)$. But, mean plasma serotonin 16 days and 30 days after treatment in ECT group was higher than Non-ECT group significantly $(p=0.048, p=$ 0.040 respectively) (Table 1 ). In ECT group, the mean plasma serotonin levels before ECT, 15 minutes, 2, 6, and 24 hours after the first ECT, and 24 hours and 30 days after the last ECT session were $197.66 \pm 81.24,211.86 \pm 79.30,204.86 \pm$ $62.14,246.14 \pm 98.60,234.76 \pm 101.42,263.71 \pm 100.14$ and $263.81 \pm 101.63 \mathrm{ng} / \mathrm{ml}$ respectively. The results of repeated measure ANOVA showed that in ECT group, mean serotonin changes were significant in different stages of measurement $(\mathrm{P}=0.007)$. In the Non- ECT group, the mean serotonin levels before drug therapy, 16 days and 30 days after beginning drug therapy were $198.93 \pm 84.38,198.40 \pm 84.98$ and $195.93 \pm$ 81.59 respectively. The results of Repeated measure test showed that in Non-ECT group, mean serotonin changes were not significant in different stages of measurement $(p=0.739)$ (Table 1, Figure 1). 


\begin{tabular}{|c|c|c|c|c|c|c|c|c|}
\hline \multirow{2}{*}{ Groups } & \multirow{2}{*}{ Before Treatment } & \multicolumn{7}{|c|}{ After Treatment } \\
\hline & & $15 \mathrm{~min}$. & 2 hours & 6 hours & 24 hours & 16 days & 30days & $* *$ p-Value \\
\hline ECT & $\begin{array}{c}197.66 \pm \\
81.24\end{array}$ & $\begin{array}{c}211.86 \pm \\
79.30\end{array}$ & $\begin{array}{c}204.86 \pm \\
62.14\end{array}$ & $\begin{array}{c}246.14 \pm \\
98.60\end{array}$ & $\begin{array}{c}234.76 \pm \\
101.42\end{array}$ & $\begin{array}{c}263.71 \pm \\
100.14\end{array}$ & $\begin{array}{c}263.81 \pm \\
101.63\end{array}$ & 0.007 \\
\hline Non-ECT & $\begin{array}{c}198.93 \pm \\
84.38\end{array}$ & & & & & $\begin{array}{c}198.40 \pm \\
84.98\end{array}$ & $\begin{array}{c}195.93 \pm \\
81.59\end{array}$ & 0.739 \\
\hline *p-value & 0.964 & & & & & 0.048 & 0.040 & \\
\hline \multicolumn{9}{|c|}{ Table 1. Comparison of Serum Serotonin Levels Within and Between the Two Groups in different Times } \\
\hline & & $* * \mathrm{p}-$ & was asses & by repeate & $\begin{array}{l} \pm \text { SD. } \\
\text { dent t-test. } \\
\text { easure ANC }\end{array}$ & & & \\
\hline
\end{tabular}

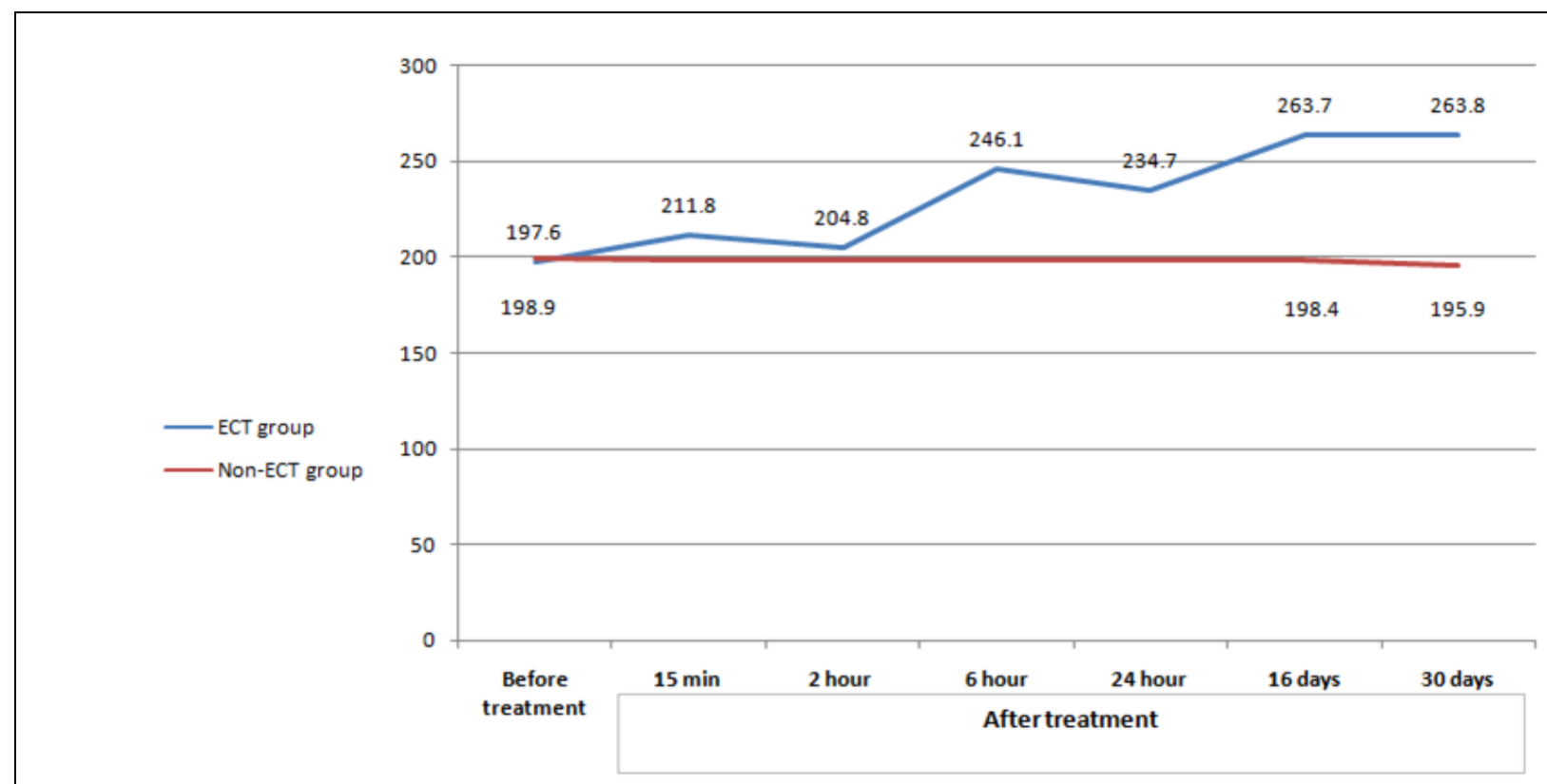

Figure 1. Mean of Serotonin Levels Changes at different Times in The Two Groups

\section{DISCUSSION}

It seems that this study is one of the few studies of the effect of ECT on plasma serotonin level. While numerous studies have examined the effects of ECT on brain serotonin, the present study investigated the effects of ECT on plasma serotonin. Our findings showed significant increments in plasma serotonin levels of the patients after ECT. Researches have suggested a weak, yet noteworthy, relationship between plasma and brain serotonin levels. Audhya et al. reported serotonin levels in plasma and urine to be significantly, but less strongly, correlated with levels of the substance in the CSF.(13) Lanzenberger et al. indicated that ECT significantly decreased the amount of serotonin-1A receptor in the cortical and subcortical regions of the brain.(14) Reductions in the levels of serotonin receptors increase serotonin levels in the brain, the CSF, and finally plasma. Likewise, Svenningsson et al. observed increased serotonin-1B receptor activity in the brains of rodents following the use of antidepressants or ECT.(15) In the present study, plasma serotonin levels increased again 6 hours after ECT. This could probably be caused by the side effects and muscular effects of ECT. Sharifi et al. evaluated the relationship between a single exhaustive exercise session and plasma serotonin and prolactin levels in male athletes. They concluded that even one session of intensive physical exercise could significantly increase the subjects' plasma serotonin levels 10 minutes after exercise.(16) Another study revealed eight weeks of aerobic exercise to cause a significant increase in plasma serotonin levels.(17) Therefore, elevated plasma serotonin levels in our patients might have also been the result of intensive muscular actions induced by ECT. ECT seems to have considerable effects on the chemical system of the body. It increases dehydroepiandrosterone sulfate (DHEAS), decreases testosterone and 17-hydroxyprogesterone (17OHP), and has no particular effects on cortisol levels.(18) Furthermore, ECT boosts the levels of prolactin, adrenocorticotropic hormone (ACTH), and cortisol, but leaves growth hormone, follicle-stimulating hormone (FSH), and luteinizing hormone (LH) levels unchanged. Hormonal responses to ECT may reflect stimulation induced by direct topical electrical activity due to convulsive action or accumulation of neurotransmitters during hypothalamic and Pituitary hormone release. Similar to our findings, previous studies have reported levels of prolactin, thyroid-stimulating hormone (TSH), ACTH, and plasma cortisol level to significantly increase immediately after ECT, but return to their initial levels in the early hours after ECT.(19,20) In the current study, however, plasma serotonin reduced two hours after ECT, but increased and steadied at all other times. Some studies have shown that ECT can be associated with an elevated risk of micro-haemorrhage in healthy people. This has also been confirmed by post-ECT patient autopsy. ${ }^{(21,22)}$ Since platelets adhere to the damaged site and begin to release serotonin during haemorrhage, the re-increase in 
serotonin level in the present research can be justified by higher serotonin release from platelets. Moreover, reduced blood circulation in some areas following both ECT and generalized convulsion (Even through convulsive injections),(23) can raise free serotonin levels. Although assessment of CSF serotonin levels through a lumbar puncture (LP) would have better clarified changes in the level of serotonin, such procedure was not ethical. Overall, we can attribute the therapeutic effects of ECT to the increased plasma serotonin levels following its application. Regardless of the reasons due to which such increments occur, the favourable effects of ECT on treatment-resistant patients with depression cannot be ignored.

\section{ACKNOWLEDGMENTS}

The researchers would like to thank Vice Chancellor for Research \& Technology, and Moradi Hospital, Rafsanjan University of Medical Sciences, Rafsanjan, Iran.

\section{Ethics}

This study was approved by the Iranian registry of clinical trials (IRCT2015032621497N2).

\section{CONCLUSIONS}

It seems that electroconvulsive therapy increases plasma serotonin levels by affecting some of the brain's structures. Perhaps the effects of electroconvulsive therapy are due to the same changes, though more studies are needed.

\section{REFERENCES}

[1] Sne Y. The effect of personal coaching process on the rehabilitation. The 15th Pacific Rim College of Psychiatrists Scientific Meeting. PRCP 2012, Seoul, Korea: Asia-pacific psychiatry, 2012.

[2] Kessler RC, Chiu WT, Demler 0, et al. Prevalence, severity and comorbidity of 12-month DSM-IV disorders in the National Comorbidity Survey Replication. Arch Gen Psychiatry 2005;62(6):617-27.

[3] Cooney GM, Dwan K, Greig CA, et al. Exercise for depression. Cochrane Database Syst Rev 2013;(9):CD004366.

[4] Saveanu RV, Nemeroff CB. Etiology of depression: genetic and environmental factors. Psychiatr Clin North Am 2012;35(1):51-71.

[5] Rapport MM, Green AA, Page IH. Serum vasoconstrictor, serotonin: isolation and characterization. J Biol Chem 1948;176(3):1243-51.

[6] Sadock BJ, Sadock VA, Ruiz P. Kaplan \& Sadocks Synopsis of psychiatry, behavioral sciences/clinical psychiatry. $11^{\text {th }}$ edn. USA: Wolters Kluwer 2015.

[7] Waite J, Easton A. The ECT Handbook. $3^{\text {rd }}$ edn. London: RCPsych Publications 2013.

[8] Bolwig TG. How does electroconvulsive therapy work? Theories on its mechanism. Can J Psychiatry 2011;56(1):13-8.

[9] Szuba MP, O'Reardon JP, Evans DL. Physiological effects of electroconvulsive therapy and transcranial magnetic stimulation in major depression. Depress Anxiety 2000;12(3):170-7.
[10] Massoodzadeeh A, Hosseini SH, Razegheian M. Comparison effects of clozapine, ECT and combination ECT and clozapine on resistance treatment of schizophrenia (Double blind). Journal of Mazandaran University of Medical Sciences 2006;15(50):7-14.

[11] Yatham LN, Liddle PF, Lam RW, et al. Effect of electroconvulsive therapy on brain 5-HT(2) receptors in major depression. The British Journal of Psychiatry 2010;196(6):474-9.

[12] Bluth $\mathrm{MH}$, Hardin RE, Tenner S, et al. Laboratory diagnosis of gastrointestinal and pancreatic disorders. In: McPherson RA, Pincus MR, eds. Henry's Clinical diagnosis and management by laboratory methods. $21^{\text {st }}$ edn. Philadelphia: Saunders Elsevier 2006.

[13] Audhya T, Adams JB, Johansen L. Correlation of serotonin levels in CSF, platelets, plasma and urine. Biochim Biophys Acta 2012;1820(10):1496-501.

[14] Lanzenberger R, Baldinger P, Hahn A, et al. Global decrease of serotonin-1A receptor binding after electroconvulsive therapy in major depression measured by PET. Mol Psychiatry 2013;18(1):93-100.

[15] Svenningsson P, Chergui K, Rachleff I, et al. Alterations In 5 -Ht1B receptor function by $\mathrm{p} 11$ in depression-like states. Science 2006;311(5757):77-80.

[16] Sharifi GH, Babai AR, Barkhordari A, et al. The effect of one exhausted exercise session on serum serotonin and prolactin level of men runners. TKJ 2012;4(1\&2):53-8.

[17] Vafamand E, Kargarfard M, Marandi M. Effects of an eight-week aerobic exercise program on dopamine and serotonin levels in addicted women in the central prison of Isfahan, Iran. Journal of Isfahan Medical School 2012;30(204):1336-47.

[18] Ozsoy S, Eşel E, Hacimusalar Y, et al. Acute and chronic effects of electroconvulsive therapy on neuroactive steroids in patients with major depressive disorder. Turk Psikiyatri Derg 2008;19(4):341-8.

[19] Markianos M, Hatzimanolis J, Lykouras L. Serotonergic and dopaminergic neuroendocrine responses of male depressive patients before and after a therapeutic ECT course. Eur Arch Psychiatry Clin Neurosci 2002;252(4):172-6.

[20] Fava M. Diagnosis and definition of treatmentresistant depression. Biol Psychiatry 2003;53(8):64959.

[21] Friedberg J. Electroshock therapy: let's stop blasting the brain. Psychology Today 1975;9(3):18-25.

[22] Ghanizadeh A, Ghanizadeh MJ, Moini R, et al. Association of vaginal bleeding and electroconvulsive therapy use in pregnancy. J Obstet Gynaecol Res 2009;35(3):569-71.

[23] Post RM, Spee AM, Weiss SRB, et al. Seizure models: anticonvulsant effects of ECT and rTMS. Prog Neuropsychopharmacol Biol Psychiatry 2000;24(8):1251-73. 